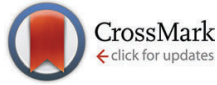

Cite this: Phys. Chem. Chem. Phys., 2014, 16, 19917

Received 15th July 2014 Accepted 6th August 2014

DOI: $10.1039 / c 4 c p 03113 j$

www.rsc.org/pccp

\title{
Structural properties of iron-phosphate glasses: spectroscopic studies and ab initio simulations
}

\author{
Pawel Stoch, ${ }^{* a}$ Wojciech Szczerba, ${ }^{\text {b }}$ Wiktor Bodnar, ${ }^{\mathrm{c}}$ Malgorzata Ciecinska, ${ }^{a}$ \\ Agata Stoch ${ }^{d}$ and Eberhard Burkel ${ }^{c}$
}

\begin{abstract}
Vitrification is the most effective method for the immobilization of hazardous waste by incorporating toxic elements into a glass structure. Iron phosphate glasses are presently being considered as matrices for the storage of radioactive waste, even of those which cannot be vitrified using conventional borosilicate waste glass. In this study, a structural model of $60 \mathrm{P}_{2} \mathrm{O}_{5}-40 \mathrm{Fe}_{2} \mathrm{O}_{3}$ glass is proposed. The model is based on the crystal structure of $\mathrm{FePO}_{4}$ which is composed of $\left[\mathrm{FeO}_{4}\right]\left[\mathrm{PO}_{4}\right]$ tetrahedral rings. The rings are optimized using the DFT method and the obtained theoretical FTIR and Raman spectra are being compared with their experimental counterparts. Moreover, the proposed model is in very good agreement with X-ray absorption fine structure spectroscopy (XANES/EXAFS) and Mössbauer spectroscopy measurements. According to the calculations the $\mathrm{Fe}^{3+}$ is in tetrahedral and five-fold coordination. The maximal predicted load of waste constituents into the glass without rebuilding of the structure is $30 \mathrm{~mol} \%$. Below this content, waste constituents balance the charge of $\left[\mathrm{FeO}_{4}\right]^{-}$tetrahedra which leads to their strong bonding to the glass resulting in an increase of the chemical durability, transformation and melting temperatures and density.
\end{abstract}

\section{Introduction}

Vitrification is the most effective method for the immobilization of hazardous waste. Toxic elements are incorporated into the glass structure and stay bonded to it. For many years borosilicate glasses have been of common use in the nuclear waste immobilization procedure. Lately the $\mathrm{Fe}_{2} \mathrm{O}_{3}-\mathrm{P}_{2} \mathrm{O}_{5}$ glasses have been of great interest, for scientific reasons and because they are considered as high capacity matrices for storage of radioactive waste. $^{1,2}$ The worldwide used borosilicate glasses for nuclear waste vitrification are not suitable for immobilization of waste with a high content of molybdenum, chromium or salts because of the low solubility of these compounds in the glass. Therefore, it is necessary to look for an alternative vitrification matrix. The next choice is the phosphate glass. However, most phosphate glasses have a low chemical durability, ${ }^{3}$ but iron as a glass component significantly increases it. The $60 \mathrm{P}_{2} \mathrm{O}_{5}-40 \mathrm{Fe}_{2} \mathrm{O}_{3}(\mathrm{Fe} / \mathrm{P}=0.67)$ glass has the highest chemical durability among others. All of them

\footnotetext{
${ }^{a}$ Faculty of Material Science and Ceramics, AGH-University of Science and Technology, 30 Mickiewicza Av, 30349 Krakow, Poland. E-mail: pstoch@agh.edu.pl; Fax: +48 12633 4630; Tel: +48 126172504

${ }^{b}$ BAM Federal Institute for Materials Research and Testing, Unter den Eichen 87, 12205 Berlin, Germany

${ }^{c}$ Institute of Physics, University of Rostock, August-Bebel-Str. 55, 18055 Rostock, Germany

${ }^{d}$ Institute of Electron Technology Krakow Division, Zablocie 39, 30701 Krakow, Poland
}

have an $\mathrm{O} / \mathrm{P}$ ratio of over 3 and are classified as polyphosphate glasses. ${ }^{4}$ There are indications that iron strengthens the chemical bonds in the glass structure making their properties comparable or even better than those of borosilicate glasses. ${ }^{1,2}$

Besides their excellent chemical durability, iron phosphate glasses have the melting temperature of about 100-200 K lower than borosilicate glass and also due to lower viscosity of the melts their homogenization time is about $1.5-3$ hours shorter. ${ }^{5}$ It is why they can be suitable for vitrifying waste containing significant quantities of volatile elements such as Cs. Moreover, iron phosphate glasses exhibit particularly high thermal stability in terms of the low crystallization ability and can be produced in large quantities without the danger of crystallization of the matrix. Nevertheless, glassy materials with crystalline particulate inclusions were also obtained in particular cases depending on the composition and heating schedule. ${ }^{1}$

Iron phosphate glasses are now considered for the vitrification of waste containing a relatively high concentration of actinide elements, a high concentration of sodium, caesium sulphate and chloride, chloride waste from pyrochemical reprocessing of $\mathrm{Pu}$ metal and waste containing various metals, radioactive ceramics, polymers or carbon. ${ }^{1,6}$

The structure of phosphate glasses can be described in a convenient way using the $\mathrm{Q}^{i}$ notation. The $\mathrm{Q}^{i}$ represents the phosphate tetrahedra, where $i$ represents the number of neighbouring P-tetrahedra linked by common bridging oxygens. ${ }^{4,7}$ Single component $\mathrm{P}_{2} \mathrm{O}_{5}$ glass is built of only $\mathrm{Q}^{3}$ tetrahedra 
which have three bridging oxygens and one non-bridging oxygen atom $(\mathrm{P}=\mathrm{O})$. Phosphate glasses can be described as a range of structures, from a three dimensional cross-linked network of $\mathrm{Q}^{3}$ tetrahedra to polymer-like metaphosphate chains of $\mathrm{Q}^{2}$ tetrahedra to glasses based on small pyro- $\left(\mathrm{Q}^{1}\right)$ and orthophosphate $\left(\mathrm{Q}^{0}\right)$ anions. The $\mathrm{Q}^{i}$ notation assumes only one type of network forming cations. In the case of iron-phosphate glasses there is a possibility that, similar to that in silicate glasses, $\mathrm{Fe}^{3+}$ could be a network former or a network modifier. Therefore the $\mathrm{Q}_{n}$ notation instead of $\mathrm{Q}^{i}$ is used in the present paper. The $\mathrm{Q}_{n}$ notation expresses the concentration of bridging oxygens per tetrahedron by varying the value of $n$. A tetrahedron fully linked into the network via four bridging oxygens is designated as a $\mathrm{Q}_{4}$ unit, while an isolated tetrahedron with no bridging oxygens is designated as a $\mathrm{Q}_{0}$ unit. The value of $n$ is thus equal to the number of bridging oxygens in a given tetrahedron. ${ }^{8}$

The local structure of iron is complicated by the fact that depending on conditions of synthesis, the glass may contain variable amounts of $\mathrm{Fe}^{2+}$ ions. It leads to extremely complex crystallography of the iron phosphate system which is composed of over 20 different crystalline phases in which iron can be present in both valence states and coordination numbers to oxygen from 4 to 6 . In the case of iron phosphate glasses the structural analogue of $\mathrm{SiO}_{4}$ tetrahedra (a main building block of silicate glasses) is $\mathrm{FePO}_{4}$ which is characteristic of a similar phase transition from $\alpha$-quartz to $\beta$-quartz at $980 \mathrm{~K}$ with alternate corner sharing of both $\left[\mathrm{FeO}_{4}\right]^{-}$and $\left[\mathrm{PO}_{4}\right]^{+}$tetrahedra. For glasses which possess excess of $\mathrm{P}_{2} \mathrm{O}_{5}$ some possible structural models were already proposed. The first model was proposed by Wedgwood. ${ }^{9}$ Here, the glass structure is built of three different units $\left[\mathrm{FeO}_{4}\right]^{-}$and $\left[\mathrm{PO}_{4}\right]^{+}$tetrahedra sharing all four vertices like in $\alpha-\mathrm{FePO}_{4}$ and $\mathrm{O}=\mathrm{PO}_{3}$ units, which are $\mathrm{PO}_{4}$ tetrahedra with one terminal double bonded oxygen and three vertices sharing single bonded oxygen atoms. In this model all of the $\mathrm{Fe}^{2+}$ cations are present as network modifiers in octahedral coordination. The next model was proposed by Marasinghe et al. ${ }^{10}$ and is based on the crystal structure of $\mathrm{Fe}_{3}\left(\mathrm{P}_{2} \mathrm{O}_{7}\right)_{2}$ in which one $\mathrm{Fe}^{2+}$ ion is present in trigonal prismatic coordination and two $\mathrm{Fe}^{3+}$ ions in octahedral coordination. On the other hand, glasses with high $\mathrm{Fe}_{2} \mathrm{O}_{3}$ content exhibit short range antiferromagnetic ordering at low temperatures, very similar to $\alpha$-quartz $\mathrm{FePO}_{4}$, which is hence the first structural model. Wright et al. ${ }^{11}$ proposed a nanoheterogenous model comprising regions with alternating $\left[\mathrm{FeO}_{4}\right]^{-}$and $\left[\mathrm{PO}_{4}\right]^{+}$corner sharing tetrahedra, together with separate regions in which the glass contains both tetrahedral $\mathrm{Fe}^{3+}$ and octahedral $\mathrm{Fe}^{2+} / \mathrm{Fe}^{3+}$ cations.

The magnetic structure of these glasses is quite complex and confirms the presence of speromagnetic ordering. ${ }^{9,12,13}$ The magnetic correlation function obtained by the neutron scattering method shows the existence of negative peaks at $3.7 \AA$ and 5.8-5.9 $\AA$, which suggests that the average magnetic moment of the atoms at this distance tends to be anti-parallel and the broad positive effect appears at 8-10 ̊ distance. ${ }^{9,10}$

It is worth mentioning that in iron-phosphate glasses part of iron is always in the ferrous state with its amount depending on the synthesis conditions from about 10 to even $100 \%$. On the other hand, during studies on immobilization of caesium, glasses with almost only ferric iron but with some $\mathrm{Cs}_{2} \mathrm{O}$ content were obtained. The structure of these glasses does not change with $\mathrm{Cs}_{2} \mathrm{O}$ content up to about $22 \mathrm{~mol} \%$, but above this threshold some structural changes are observed. ${ }^{14,15}$ Analogously, investigations on immobilization of $\mathrm{Na}_{2} \mathrm{SO}_{4}$ in similar glasses showed an increase in the stability of the glass structure up to about $30 \mathrm{~mol} \%$ and rebuilding it for higher contents of $\mathrm{Na}_{2} \mathrm{O} .{ }^{16}$

Motivated by the aforementioned studies, a structural model of the $60 \mathrm{P}_{2} \mathrm{O}_{5}-40 \mathrm{Fe}_{2} \mathrm{O}_{3}$ glass is presented. The model was optimised using the DFT method. The calculated theoretical FTIR and Raman spectra were compared with the experimental results. Moreover, the proposed model was evaluated applying EXAFS/XANES and Mössbauer spectroscopy and using other results known from the literature.

\section{Experimental}

Glass containing $40 \mathrm{~mol} \% \mathrm{Fe}_{2} \mathrm{O}_{3}$ and $60 \mathrm{~mol} \% \mathrm{P}_{2} \mathrm{O}_{5}$ was prepared from high purity $\mathrm{NH}_{4} \mathrm{H}_{2} \mathrm{PO}_{4}$ and $\mathrm{Fe}_{2} \mathrm{O}_{3}$. Approximately 20 mass\% overweight of $\mathrm{NH}_{4} \mathrm{H}_{2} \mathrm{PO}_{4}$ was used to compensate $\mathrm{P}_{2} \mathrm{O}_{5}$ losses during melting of the batch due to evaporation. The batch was melted for $2 \mathrm{~h}$ at $1373 \mathrm{~K}$ in an $\mathrm{Al}_{2} \mathrm{O}_{3}$ crucible in an electric furnace with the furnace atmosphere as close to natural as possible. The melt was vitrified by casting onto a steel plate and then crushed. The chemical composition of the obtained glass was checked by X-ray fluorescence spectroscopy and by $\mathrm{X}$-ray diffraction to be amorphous.

Spectroscopic studies in the middle infrared (MIR) regions (4000-400 $\mathrm{cm}^{-1}$ ) were carried out using a Fourier transform spectrometer Digilab FTS-60MVPC (Bio-Rad). The standard transmission technique was used. A sample of the glass was prepared as the standard $\mathrm{KBr}$ pellets and FITR spectra were collected after 256 scans with a resolution of $4 \mathrm{~cm}^{-1}$.

Raman spectra of the glass have been collected using a FTS 6000 Bio-Rad Spectrometer with the Raman section (with Nd:YAG Spectra Physics T10, $1064 \mathrm{~nm}$ laser). Spectra were collected after 10000 scans with a resolution of $4 \mathrm{~cm}^{-1}$.

The X-ray absorption fine structure (XAFS) spectroscopy experiment was carried out at the BAMline beamline at a BESSY II storage ring in Berlin, Germany. ${ }^{17}$ The measurements were performed in the transmission mode at the iron K-edge (7112 eV) using two $50 \mathrm{~mm}$ long ionization chambers (Oxford Danfysik IC Plus 50). The first chamber monitoring the incident beam intensity was filled with air, the second one detecting the absorption signal behind the sample was filled with argon, both at ambient pressure. This gave a transmittance of 0.9 for the first chamber and 0.25 for the second one in the energy range of interest. The energy was scanned using a $\mathrm{Si}(111)$ double crystal monochromator. The X-ray absorption near-edge structure (XANES) region was scanned with an energy step of $1 \mathrm{eV}$, whereas the extended X-ray absorption fine structure (EXAFS) was recorded with a constant step in the momentum space ( $k$-space) of $0.05 \AA^{-1}$ up to $k_{\max }=15 \AA^{-1}\left(E_{\max }=7968 \mathrm{eV}\right)$. The acquisition time per point 
was $4 \mathrm{~s}$. The whole XAFS spectrum of the sample was recorded twice and averaged afterwards. The averaged spectrum underwent the standard procedure for obtaining the XAFS data using the Ifeffit (ver. 1.2.11c) software package. ${ }^{18}$ The forward Fourier transform of the EXAFS part of the spectrum was performed applying a Hannig-type window in the range 2 to $9 \AA^{-1}$ and a slope of $d_{k}=1.0$. Such settings allowed for a good compromise between the maximum range of available data and the distortions induced by the noise stemming from data points with high $k$.

In the transmission XAFS experiment the studied glass was used as a thin powder sample with a layer thickness of $10 \mu \mathrm{m}$. The layer thickness $d$ was chosen so that $\mu d \approx 1$, where $\mu$ is the linear absorption factor of the sample. This minimises the influence of the so called thickness effect ${ }^{19}$ resulting from inhomogeneity of the layer, and causes damping of EXAFS oscillations. This in turn makes the evaluation of the coordination numbers unreliable. These, however, are one of the main parameters of interest of this XAFS study. The criterion chosen allows for a good balance between the negative impact of the thickness effect and a sufficient amount of absorbing material for a good signal-to-noise ratio. ${ }^{20}$

The ${ }^{57}$ Fe Mössbauer spectroscopy studies were performed in transmission geometry at room temperature and at $77 \mathrm{~K}$ using a $25 \mathrm{mCi}{ }^{57} \mathrm{Co} \gamma$-source embedded in the $\mathrm{Rh}$ matrix. The source was mounted onto a FAST Comtec Mössbauer drive unit working in constant velocity mode. Mössbauer transmission spectra were collected in a velocity range $\pm 4 \mathrm{~mm} \mathrm{~s}^{-1}$ with 1024 channels before folding. The spectrometer was calibrated using standard $\alpha$-Fe foil. The obtained spectra were deconvoluted with an application of two Voigt line shapes and Extended Voigt Based Fits $(\mathrm{xVBF})$ were used to model distribution of iron sites in the amorphous glass. ${ }^{21,22}$

Density Functional Theory calculations at the B3LYP theory level were performed using Gaussian 09 D 0.1 software package. ${ }^{23}$ For all calculations the same 6-311G(d) basis set was used. The composition of the computed clusters was close to stoichiometry of the synthesised basis glass. Geometry optimization was performed for all of the computed clusters and as a result theoretical FTIR and Raman spectra were calculated. Hydrogen atoms were used to terminate broken bonds at the model boundary.

\section{Results}

\subsection{DFT simulations}

Crystallization of $60 \mathrm{P}_{2} \mathrm{O}_{5}-40 \mathrm{Fe}_{2} \mathrm{O}_{3}$ glass leads to the formation of two phases, namely $\alpha-\mathrm{FePO}_{4}$ and $\mathrm{Fe}_{2} \mathrm{P}_{2} \mathrm{O}_{7}$, whose proportions strongly depend on the ratio of $\mathrm{Fe}^{3+} / \mathrm{Fe}^{2+}$ ions. ${ }^{16}$ Such glass structure should somehow reflect the particular crystallising phases. For a glass with only ferric iron crystallization of $\alpha-\mathrm{FePO}_{4}$ should be observed, which indeed is the main crystal phase in the case of the phosphate glasses with high $\mathrm{Fe}^{3+}$ content. The $\alpha-\mathrm{FePO}_{4}$ crystal structure, presented in Fig. 1, is composed of $\left[\mathrm{FeO}_{4}\right]^{-}$and $\left[\mathrm{PO}_{4}\right]^{+}$tetrahedra which share their vertices with each other and form even membered rings. In this structure every

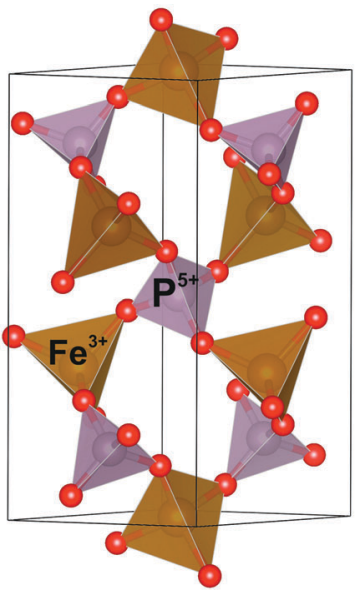

Fig. 1 Crystal structure of $\alpha-\mathrm{FePO}_{4}$.

$\mathrm{P}^{5+}$ cation is joined to four oxygen $\mathrm{O}^{2-}$ anions by a single bond. This leads to uncompensated charge +1 of $\left[\mathrm{PO}_{4}\right]$ tetrahedra. On the other hand iron is present as $\mathrm{Fe}^{3+}$ cations and forms $\left[\mathrm{FeO}_{4}\right]^{-}$ tetrahedra. Thus an alternating arrangement of $\left[\mathrm{PO}_{4}\right]^{+}$and $\left[\mathrm{FeO}_{4}\right]^{-}$tetrahedra leads to charge neutrality of the crystal.

It is worth mentioning that an excess of $10 \mathrm{~mol} \%$ of $\mathrm{P}_{2} \mathrm{O}_{5}$ exists in the studied glass. It can lead to the formation of similar even membered rings but smaller ones. This can result in breaking some of the $\mathrm{P}-\mathrm{O}-\mathrm{Fe}$ bonds and in the formation of $\mathrm{P}=\mathrm{O}$ bonds and thus can lead to transformation of the structural units $\mathrm{Q}_{4}$ to $\mathrm{Q}_{3}$. Taking this into account, a fully optimized ring cluster (Fig. 2a) is proposed and for the purpose of further consideration it will be designated as the ring. The total energy per atom of the ring is -191.99 a.u. per at. Such rings can join each other and form the glass (Fig. $2 \mathrm{~b}$ and $\mathrm{c}$ ). The ratio of $\mathrm{P} / \mathrm{Fe}$ in the ring is the same as the stoichiometry of the melt but there is a lack of one oxygen atom. This enhances reduction conditions of the melt and can reduce part of $\mathrm{Fe}^{3+}$ to $\mathrm{Fe}^{2+}$. In the proposed ring the distance between two $\mathrm{Fe}$ ions is approximately $3.37 \AA$ and it is comparable but smaller than
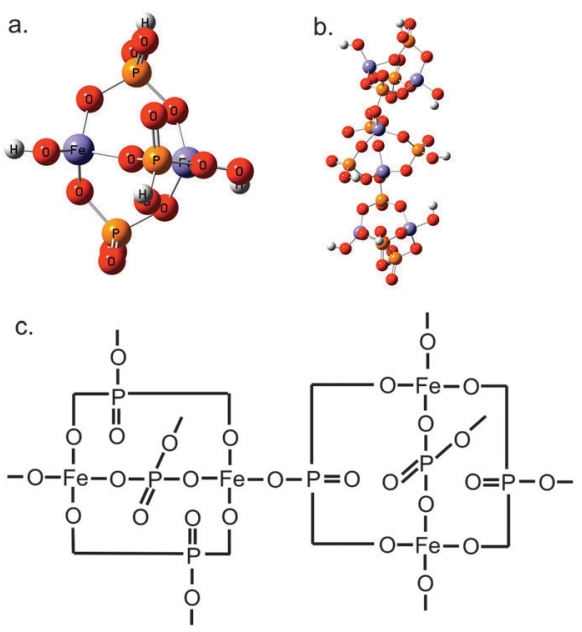

Fig. 2 Proposed and optimised ring (a), an exemplary connection of the rings (b), and a simplified scheme of the connection of two rings (c). 

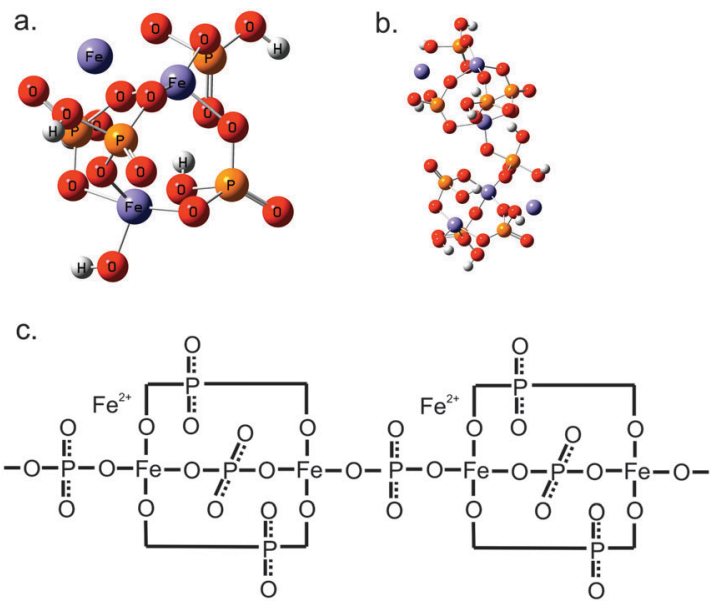

Fig. 3 Proposed and optimised unit of the $60 \mathrm{P}_{2} \mathrm{O}_{5}-40 \mathrm{Fe}_{2} \mathrm{O}_{3}$ glass (a), an exemplary connection of the units (b) and a simplified scheme of the connection of two units (c).

the experimental value $3.7 \AA^{11,22}$ According to neutron diffraction studies ${ }^{11}$ these two Fe ions should be aligned anti-parallel. Every Fe ion in the ring has the next Fe neighbour in the second ring at distances approximately $5.6 \AA$ and $8.7 \AA$. The closer one should be coupled anti-parallel and the second one parallel, ${ }^{11}$ which can lead to a magnetic frustration of the system. In the presented model the whole iron is in the $\mathrm{Fe}^{3+}$ state and forms $\left[\mathrm{FeO}_{4}\right]^{-}$tetrahedra with an unbalanced charge.

The reducing conditions of the melt change a part of ferric iron to ferrous, which can lead to breaking of some of the rings and changing the role of iron from a network former to a network modifier. The remnant $\mathrm{P}^{5+}$ and $\mathrm{O}^{2-}$ ions, which are left after decomposition of a part of the rings, can be joined to the remnant rings. The proposed new kind of structural unit of the glass after the optimization procedure is shown in Fig. 3a and for the purpose of further consideration it will be designated as the unit. The total energy of the unit is -247.55 a.u. per at and is lower than in the case of the ring. The stoichiometry of the unit is also close to the theoretical. The remnant $\mathrm{P}^{5+}$ and $\mathrm{O}^{2-}$ after decomposition of the ring are joined as new $\left[\mathrm{PO}_{4}\right]$ tetrahedra to the $\left[\mathrm{FeO}_{4}\right]$ tetrahedra. The rest of the oxygen anions leads to transformation of the structural units $\mathrm{Q}_{3}$ to $\mathrm{Q}_{2}$ which depolymerises the glass network. There are three different iron sites in the unit. Two sites in which iron is the glass network former: one in distorted tetrahedral coordination and the second one, where in the closest shell there is four oxygen atoms at a distance of about $1.86 \AA$ and one at about $2.0 \AA$. The third $\mathrm{Fe}^{2+}$ ion plays the role of a network modifier and can be bonded to non-bridging oxygen of $\left[\mathrm{PO}_{4}\right]$ tetrahedra. It is worth mentioning that this $\mathrm{Fe}^{2+}$ ion can also cross-link with the units that may increase the chemical durability. The units can be bonded with each other and they form a chain like structure as presented in Fig. 3b and c. The distance between Fe ions in the ring is approximately $3.66 \AA$. The distances between Fe ions in the next unit are $5.45 \AA$ and $7.49 \AA$. These values are comparable with the experimental peaks observed in the magnetic correlation function. ${ }^{11}$ The average $\mathrm{P}-\mathrm{O}_{\mathrm{nb}}$ (non-bridging oxygen) distance is $1.47 \AA$ and the $\mathrm{P}-\mathrm{O}_{\mathrm{b}}$ (bridging oxygen) distance is about $1.61 \AA$ A. Similar values and differences between them were previously observed experimentally ${ }^{11,24,25}$ and also were simulated using classical molecular dynamics. ${ }^{26}$ Moreover, Hoppe et al. ${ }^{25}$ obtained experimentally $\mathrm{P}-\mathrm{O}_{\mathrm{nb}}$ and $\mathrm{P}-\mathrm{O}_{\mathrm{b}}$ distances equal to $1.46 \AA$ and $1.62 \AA$ respectively in $\mathrm{Q}_{2}$ units, which are mostly observed in the simulated cluster. The neutron real space correlation function is characteristic of three peaks i.e. $\mathrm{P}-\mathrm{O}, \mathrm{Fe}-\mathrm{O}$ and $\mathrm{O}-\mathrm{O}$ at $1.50-1.55 \AA$, 1.89-1.93 $\AA$ and 2.47-2.51 $\AA$, respectively ${ }^{24,25,27}$ Similar mean lengths obtained according to the calculations are $1.57 \AA$, $1.90 \AA$ and $2.49 \AA$, respectively.

Natural Bond Orbital (NBO) ${ }^{28}$ analysis implemented in the Gaussian code was used to calculate the natural ionicity of a bond, as defined in ref. 29. The natural ionicity is zero for pure covalent bonds and can achieve any value between 0 and 1 for a pure ionic bond. The natural ionicity was lowest for the $\mathrm{P}-\mathrm{O}$ bond (0.611) which as expected is more covalent than the $\mathrm{Fe}^{3+}-\mathrm{O}$ bond (0.709) and $\mathrm{Fe}^{2+}-\mathrm{O}$ bond $(0.823)$ which are the most ionic in nature.

\subsection{Raman spectroscopy}

Raman spectroscopy has been widely used as an effective tool to study structural aspects of phosphate crystals and glasses. The frequency of the stretching vibrations of $\mathrm{P}-\mathrm{O}$ bonds changes with the number of bridging oxygen atoms. The proper association of the measured peaks with the different $\mathrm{P}-\mathrm{O}$ vibrational modes can be used to estimate structural elements of the studied glasses. This is especially important in the case of iron-phosphate glasses, in which because of high concentration of iron the NMR method could not be successfully used to determine the type and quantity of different phosphorous structural units.

The experimental Raman spectrum of the $60 \mathrm{P}_{2} \mathrm{O}_{5}-40 \mathrm{Fe}_{2} \mathrm{O}_{3}$ glass in the frequency region $200-2000 \mathrm{~cm}^{-1}$ is presented in Fig. 4. The first low frequency peak appears at about $350 \mathrm{~cm}^{-1}$ and is related to bending vibrations of $\mathrm{PO}_{4}$ units with a cation as the modifier. ${ }^{30}$ Overlapping of bending and torsional vibrations of iron oxygen polyhedral and pyrophosphate groups $\left(\mathrm{P}_{2} \mathrm{O}_{7}\right)^{4-}$ can be observed at $525 \mathrm{~cm}^{-1} \cdot{ }^{31-34}$ The peaks below $600 \mathrm{~cm}^{-1}$ are in general related to different network bending modes. The peak in the range from 700 to $800 \mathrm{~cm}^{-1}$ is due to $\mathrm{P}-\mathrm{O}-\mathrm{P}$ symmetric

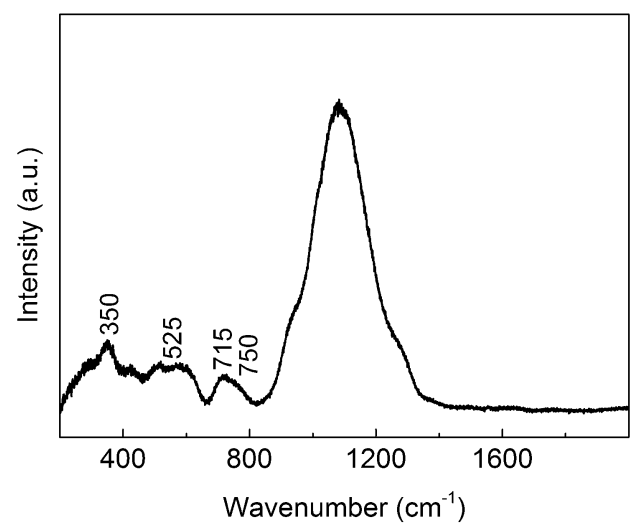

Fig. 4 The collected Raman spectrum of the $60 \mathrm{P}_{2} \mathrm{O}_{5}-40 \mathrm{Fe}_{2} \mathrm{O}_{3}$ glass. 


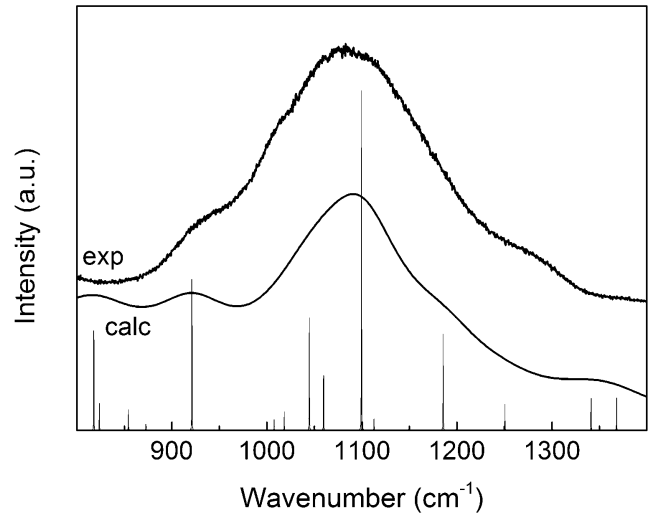

Fig. 5 The experimental and the calculated Raman spectra of the $60 \mathrm{P}_{2} \mathrm{O}_{5}-$ $40 \mathrm{Fe}_{2} \mathrm{O}_{3}$ glass.

stretch vibrations of $\mathrm{Q}^{2}$ and $\mathrm{Q}^{1}$ units. This peak is a convolution of two peaks i.e. one centred at about $715 \mathrm{~cm}^{-1}$ and the next centred at $750 \mathrm{~cm}^{-1} \cdot{ }^{31-34}$ The first one can be assigned to vibrations of the two joined $\mathrm{Q}^{2}$ units and the second one to those of $\mathrm{Q}^{1}$ units.

At higher frequencies a large and asymmetric peak consisting of two smaller and strongly convoluted Gaussian lines can be observed. The experimental spectra in the narrower range of $850-1350 \mathrm{~cm}^{-1}$ is presented in Fig. 5 .

Additionally, Fig. 5 presents the calculated Raman spectrum of the $60 \mathrm{P}_{2} \mathrm{O}_{5}-40 \mathrm{Fe}_{2} \mathrm{O}_{3}$ glass, determined assuming the proposed unit. The calculated spectrum was scaled by a scaling factor of $0.96^{35}$ and the same peak half width at the half height of $40 \mathrm{~cm}^{-1}$ was used. From Fig. 5, it is evident that the experiment and the simulation are in a very good agreement. The simulation allowed to identify, assign and describe the main features of the spectra. The bands at about $920 \mathrm{~cm}^{-1}$ and $1050 \mathrm{~cm}^{-1}$ can be ascribed to symmetric and asymmetric stretching vibrations of Fe-O-P bonds, respectively. The highest Raman activity was observed at $1100 \mathrm{~cm}^{-1}$ and lower for higher frequencies at about $1200 \mathrm{~cm}^{-1}$ can be identified as symmetric and asymmetric vibrations of $\mathrm{Q}^{2}$ units.

Some similarity between the $60 \mathrm{P}_{2} \mathrm{O}_{5}-40 \mathrm{Fe}_{2} \mathrm{O}_{3}$ glass and a quartz like compound $\alpha-\mathrm{FePO}_{4}$, can also be observed. This indicates that the crystal structure of this compound, based on tetrahedral $\left[\mathrm{PO}_{4}\right]$ and $\left[\mathrm{FeO}_{4}\right]$ units, is much closer to the glass structure than the orthorhombic form of $\mathrm{FePO}_{4}$, based on $\left[\mathrm{PO}_{4}\right]$ tetrahedra and $\left[\mathrm{FeO}_{6}\right]$ octahedral units, ${ }^{30}$ which additionally supports the proposed model.

\subsection{Infrared spectroscopy}

The experimental FTIR spectrum of $60 \mathrm{P}_{2} \mathrm{O}_{5}-40 \mathrm{Fe}_{2} \mathrm{O}_{3}$ glass in the frequency range $400-1500 \mathrm{~cm}^{-1}$ is presented in Fig. 6 . The obtained spectrum is typical for iron phosphate glasses with the largest broad intensity band at $1000-1300 \mathrm{~cm}^{-1}$. The spectrum is a convolution of many overlapping Gaussian components and a clear extraction of the particular components in this case is rather difficult.

For the proposed unit, a theoretical FTIR spectrum was also calculated and compared with its experimental counterpart (Fig. 6).

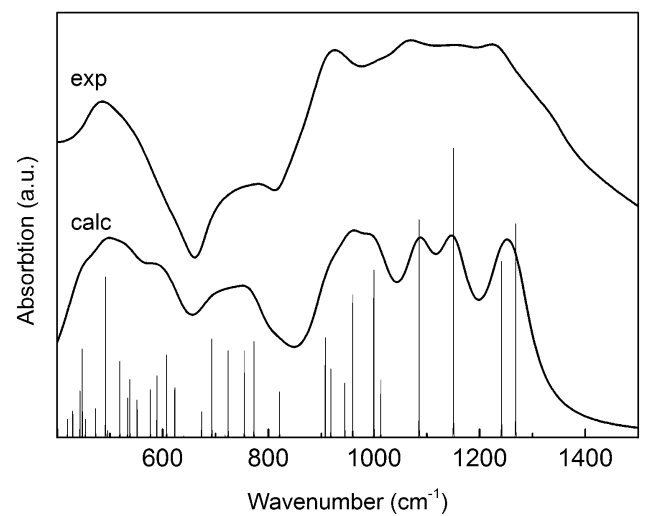

Fig. 6 The experimental and the calculated FTIR spectra of the $60 \mathrm{P}_{2} \mathrm{O}_{5}-$ $40 \mathrm{Fe}_{2} \mathrm{O}_{3}$ glass.

The spectrum was scaled using the same scaling factor and the same peak half width which was used in the case of the Raman measurement. From Fig. 6, it can be clearly seen that a very good agreement was achieved between the experiment and the simulation. The comparison of both experimental and simulated spectra allowed for assigning and describing the main features of the spectra. The collected spectrum is a convolution of many different vibrations and it can be divided into five characteristic regions. The first region in the wavenumber range of $500-600 \mathrm{~cm}^{-1}$ originates from the bending vibrations of $\mathrm{Fe}-\mathrm{O}-\mathrm{P}$ bonds. Then at higher frequencies of about $700-800 \mathrm{~cm}^{-1}$ and $900-1000 \mathrm{~cm}^{-1}$ symmetric and asymmetric vibrations of the Fe-O-P rings are evidenced, respectively. The next region of $1080-1150 \mathrm{~cm}^{-1}$ can be ascribed to stretching vibrations of bridging oxygen atoms in the $\mathrm{Q}_{2}$ units and the last region at approximately $1250 \mathrm{~cm}^{-1}$ can be identified as stretching vibrations of $\mathrm{P}=\mathrm{O}$ bonds in the $\mathrm{Q}_{2}$ units.

\subsection{Mössbauer spectroscopy}

Mössbauer spectroscopy is a very powerful experimental method for investigating the oxidation state of iron atoms and their local environment. It is also sensitive to fine changes of their local environment caused by the first and even second neighbours of tested iron atoms. In the case of amorphous materials like glasses, the interpretation of a Mössbauer spectra is not so unambiguous like for crystalline compounds. In crystalline compounds every crystallographic iron site could be observed as one component of the spectrum. In disordered amorphous materials there are many different local iron environments and every one of them is described by a different set of hyperfine interaction parameters. As a consequence, the collected spectrum is a composition of many individual components. In oxide glasses every iron cation has only oxygen anions in the first neighbourhood, but deviations in coordination or ironoxygen distance etc. should reflect the observed effect and the hyperfine interaction parameters. In the case of amorphous materials, one method for processing the spectra is an extended Voigtian based analysis (xVBF), which was described in detail elsewhere. ${ }^{21,22}$ In this method every iron atom site is given by Gaussian distribution of the independent isomer shift 


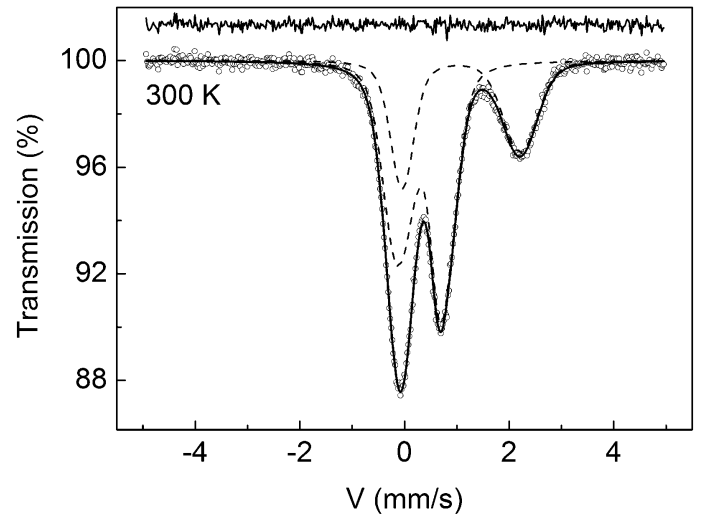

Fig. $7{ }^{57} \mathrm{Fe}$ transmission Mössbauer spectrum of the $60 \mathrm{P}_{2} \mathrm{O}_{5}-40 \mathrm{Fe}_{2} \mathrm{O}_{3}$ glass at $300 \mathrm{~K}$.

and quadrupole splitting due to some randomness in the local environment of iron.

The ${ }^{57} \mathrm{Fe}$ transmission Mössbauer spectra collected at $300 \mathrm{~K}$ and $77 \mathrm{~K}$ are presented in Fig. 7 and 8, respectively.

The obtained spectra are typical for iron-phosphate glasses. ${ }^{36}$ In Fig. 7 and 8 the coexistence of ferric and ferrous iron in the glass can be clearly observed. Both spectra were fitted assuming two different iron sites, namely one ferric and one ferrous site. In order to obtain a reasonable fit, the ferric component was modelled using two Gaussian distributions of the isomer shift. The probabilities of both distributions were set to 0.5 each and fixed during the fitting procedure. In this way, three different iron positions in the proposed glass unit could be distinguished i.e. one ferrous and one ferric, in which iron cations can be equally distributed among two different sites in the ring. As a consequence of the proposed fitting procedure, a very high consistency was obtained between the experimental Mössbauer spectra and the resulting fits, with a goodness parameter $\chi^{2}=$ 1.00 for both spectra collected at $295 \mathrm{~K}$ and $77 \mathrm{~K}$. Fig. 7 and 8 also show differential patterns between the fits and the experimental points. The hyperfine interaction parameters for the $60 \mathrm{P}_{2} \mathrm{O}_{5}-40 \mathrm{Fe}_{2} \mathrm{O}_{3}$ glass at $300 \mathrm{~K}$ and $77 \mathrm{~K}$ are presented in Table 1 , namely: $A$ - area of the site, $\mathrm{Pp}$ - probability of the component,

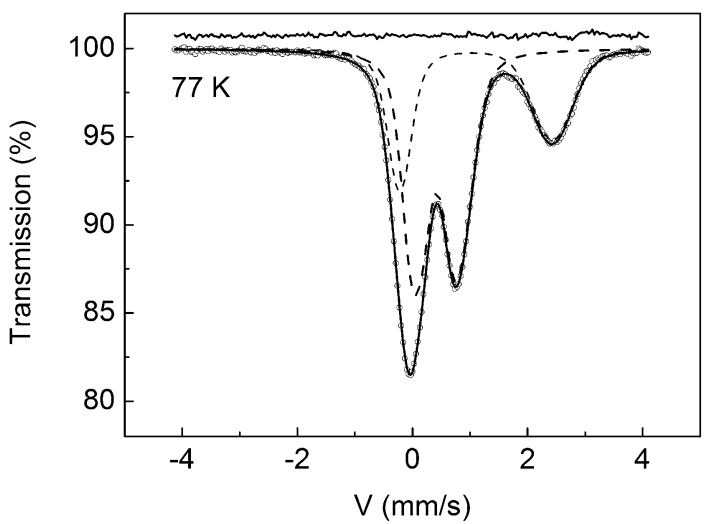

Fig. $8{ }^{57} \mathrm{Fe}$ transmission Mössbauer spectrum of the $60 \mathrm{P}_{2} \mathrm{O}_{5}-40 \mathrm{Fe}_{2} \mathrm{O}_{3}$ glass at $77 \mathrm{~K}$.
Table 1 The hyperfine interaction parameters of $60 \mathrm{P}_{2} \mathrm{O}_{5}-40 \mathrm{Fe}_{2} \mathrm{O}_{3}$ glass at $300 \mathrm{~K}$ and $77 \mathrm{~K}$

\begin{tabular}{|c|c|c|c|c|c|c|c|}
\hline No. & $A(\%)$ & Pp (\%) & $\begin{array}{l}\text { IS } \\
\left(\mathrm{mm} \mathrm{s}^{-1}\right)\end{array}$ & $\begin{array}{l}\sigma_{\mathrm{IS}} \\
\left(\mathrm{mm} \mathrm{s}^{-1}\right)\end{array}$ & $\begin{array}{l}\mathrm{QS} \\
\left(\mathrm{mm} \mathrm{s}^{-1}\right)\end{array}$ & $\begin{array}{l}\sigma_{\mathrm{QS}} \\
\left(\mathrm{mm} \mathrm{s}^{-1}\right)\end{array}$ & $r(\mathrm{IS}, \mathrm{QS})$ \\
\hline \multicolumn{8}{|c|}{$300 \mathrm{~K}$} \\
\hline \multirow[t]{2}{*}{1} & 66.1 & 0.5 & $0.326(10)$ & $0.141(10)$ & $0.846(10)$ & $0.201(10)$ & -0.510 \\
\hline & & 0.5 & $0.541(10)$ & $0.203(10)$ & & & \\
\hline 2 & 33.9 & 1.0 & $1.108(8)$ & $0.173(8)$ & $2.256(20)$ & $0.335(20)$ & 0.460 \\
\hline \multicolumn{8}{|c|}{$77 \mathrm{~K}$} \\
\hline \multirow[t]{2}{*}{1} & 63.5 & 0.5 & $0.442(5)$ & $0.044(5)$ & $0.737(5)$ & $0.219(5)$ & 0.296 \\
\hline & & 0.5 & $0.636(5)$ & $0.091(5)$ & & & \\
\hline 2 & 36.5 & 1.0 & $1.205(4)$ & $0.182(4)$ & $2.654(9)$ & $0.299(9)$ & 0.615 \\
\hline
\end{tabular}
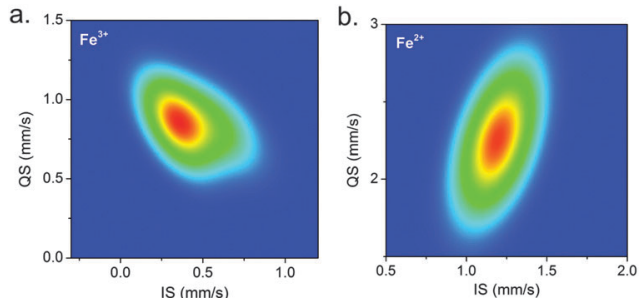

Fig. 9 Contour map of the probability distribution of $\mathrm{Fe}^{3+}$ (a) and $\mathrm{Fe}^{2+}$ (b) ions as a function of IS and QS at $300 \mathrm{~K}$.
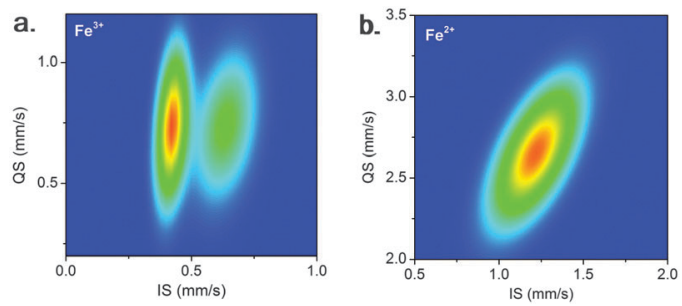

Fig. 10 Contour map of the probability distribution of $\mathrm{Fe}^{3+}$ (a) and $\mathrm{Fe}^{2+}$ (b) ions as a function of IS and QS at $77 \mathrm{~K}$.

IS - isomer shift, QS - quadrupole splitting, $\sigma_{\mathrm{IS}}$ and $\sigma_{\mathrm{QS}}-$ Gaussian widths of the distribution of the isomer shift and quadruple splitting, respectively and $r(\mathrm{IS}, \mathrm{QS})$ - correlation parameter between IS and QS.

Fig. 9 and 10 present contour maps of the probability distributions of $\mathrm{Fe}^{3+}$ and $\mathrm{Fe}^{2+}$ cations as a function of IS and QS at $300 \mathrm{~K}$ and $77 \mathrm{~K}$, respectively. Iron was introduced into the melt only in the $\mathrm{Fe}^{3+}$ form, but in the tested glass approximately $34 \%$ of iron is present as $\mathrm{Fe}^{2+}$ ions (Table 1, component 2). For other phosphate minerals, the isomer shift of $\mathrm{Fe}^{2+}$ cations in the octahedral and distorted bipyramidal coordination lies in the range of $1.15-1.27 \mathrm{~mm} \mathrm{~s}^{-1}$ and $1.10-1.16 \mathrm{~mm} \mathrm{~s}^{-1}$, respectively. ${ }^{35}$ The probability distribution of $\mathrm{Fe}^{2+}$ has the IS mean value of $1.108 \mathrm{~mm} \mathrm{~s}^{-1}$ at $300 \mathrm{~K}$, which suggests that most of the $\mathrm{Fe}^{2+}$ ions are present in the distorted bipyramidal coordination. The value of IS for $\mathrm{Fe}^{2+}$ in phosphates also strongly depends on the $\mathrm{Fe}-\mathrm{O}$ bond distance. According to ref. 37 and the obtained IS value, the mean $\mathrm{Fe}^{2+}-\mathrm{O}$ distance can be estimated as $2.0 \AA$ and is comparable to $2.1 \AA$ estimated by Hoppe et al..$^{38}$ in similar glasses. On the other hand, the distribution is wide 
$\sigma_{\mathrm{QS}}=0.335 \mathrm{~mm} \mathrm{~s}^{-1}$ (Fig. 9b), which indicates that a part of the iron $\mathrm{Fe}^{2+}$ cations is present also in the octahedral coordination. The existence of $\mathrm{Fe}^{2+}$ in six- and five-fold coordination was confirmed previously by a neutron diffraction study. ${ }^{24}$

About $66 \%$ of iron in the investigated glass occurs in the $\mathrm{Fe}^{3+}$ form. According to the proposed structure of the glass, there are two different iron sites in the ring. One tetrahedral coordinated and one in fivefold coordination. These two sites are equally populated which was assumed during the fitting procedure by fixing probabilities of two IS Gaussian components. The value of IS differs significantly for these two components. The lower IS is about $0.326 \mathrm{~mm} \mathrm{~s}^{-1}$ at $300 \mathrm{~K}$ which in the experimental error range is close to the value $0.31 \mathrm{~mm} \mathrm{~s}^{-1}$, which was previously reported for tetrahedral coordinated iron embedded in $\alpha-\mathrm{FePO}_{4} \cdot{ }^{39}$ The higher IS component can be assigned to iron in a higher coordination like fivefold, which is predicted by the proposed model. It is also worth mentioning that the distribution of ${ }^{\mathrm{IV}} \mathrm{Fe}^{3+}$ hyperfine interaction parameters is narrower than the distribution of ${ }^{\mathrm{V}} \mathrm{Fe}^{3+}$, which suggests a higher order of the tetrahedral $\mathrm{Fe}^{3+}$ surroundings. On the other hand, a relatively high value of QS for this site indicates a strong distortion thereof.

The mean value of the isomer shift of $\mathrm{Fe}^{3+}$ iron at $300 \mathrm{~K}$ is $0.433 \mathrm{~mm} \mathrm{~s}^{-1}$. By comparison to silicate glasses, it is often related to octahedral or distorted octahedral coordination but it should be also noted that the mean values of the isomer shifts in phosphate minerals are higher than in the case of silicate minerals, although the $\mathrm{Fe}-\mathrm{O}$ mean bond lengths are similar. This can be explained by a different covalence of the Si-O and the $\mathrm{P}-\mathrm{O}$ bonds. The $\mathrm{Si}-\mathrm{O}$ bonds in silicate minerals are more ionic than $\mathrm{P}-\mathrm{O}$ bonds. This leads to a more covalent character of the bond in phosphates and thus oxygen atoms are more effective in withdrawing s-electron density from iron nuclei, which results in higher values of the isomer shift.

The hyperfine interaction parameters obtained for the $60 \mathrm{P}_{2} \mathrm{O}_{5}-$ $40 \mathrm{Fe}_{2} \mathrm{O}_{3}$ glass at $77 \mathrm{~K}$ are similar to those at $300 \mathrm{~K}$. The values of IS at low temperature are higher, which is expected taking into account the second-order Doppler shift. The difference between isomer shifts IS values at $77 \mathrm{~K}$ and $300 \mathrm{~K}$ is approximately $0.1 \mathrm{~mm} \mathrm{~s}^{-1}$ and it is almost constant. This value is close to the value obtained previously for comparable iron-phosphate glasses. ${ }^{40}$ It is also worth mentioning that the difference between Gaussian components at iron site 1 (Table 1 ) is about $0.2 \mathrm{~mm} \mathrm{~s}^{-1}$ and is temperature independent. In the similar way, the QS values measured at low temperature are higher. The difference of QS in the case of $\mathrm{Fe}^{3+}$ and $\mathrm{Fe}^{2+}$ sites is also in agreement with literature. $^{39}$ The distribution of hyperfine interaction parameters for $\mathrm{Fe}^{2+}$ ions (Fig. $9 \mathrm{~b}$ and 10b) is almost the same, and at low temperature this distribution is a little bit narrower. The biggest difference is observed in distribution of the hyperfine parameters for $\mathrm{Fe}^{3+}$ ions (Fig. 9a and 10a). The lower temperature distribution is also narrower and the existence of two iron sites is easily resolved.

The similarity between the hyperfine interaction parameters obtained at two different temperatures can be a confirmation of stability of the proposed solution.

\subsection{EXAFS/XANES}

The background subtracted EXAFS spectrum of the $60 \mathrm{P}_{2} \mathrm{O}_{5}-$ $40 \mathrm{Fe}_{2} \mathrm{O}_{3}$ glass in the $k$-space is presented in Fig. 11a. It shows only one major frequency in the oscillation pattern, which is characteristic of amorphous materials. ${ }^{41}$ This owes to the fact that the EXAFS is an interference effect and due to the random character of the atomic structure in glass only the nearest neighbours can contribute significantly to the constructive interference. The Fourier transformed EXAFS function, presented in Fig. 11b, shows that besides the major contribution from the nearest neighbours, some signals do come from the farther shells, but it is significantly weaker due to the disorder. For distances beyond 4.5 Å no signal is present. Thus, the only significant signal comes from the first coordination shell.

In order to interpret the EXAFS data quantitatively an analysis employing calculations using the FEFF $9 \operatorname{code}^{42}$ was carried out. Based on structural data available for this type of glass ${ }^{24,43}$ a quick first shell theory model has been established. The model has a variable $\mathrm{N}$-fold coordination symmetry with a $\mathrm{Fe}-\mathrm{O}$ distance of $1.96 \AA$. The fit is carried out in the real part of the $R$-space using $k_{\mathrm{w}}=1,2,3$. The free parameters are: Debye-Waller factor $\left(\sigma^{2}\right)$, inner core potential correction $\left(\Delta E_{0}\right)$, mean bond length distortion $(\Delta r)$ and coordination number $(N)$. The amplitude reduction factor $\left(S_{0}{ }^{2}\right)$, taking care of the EXAFS signal damping due to multiple-body effects during the absorption process, was set to 0.69 , based on the analysis of pure metallic Fe standards. The fit gives the following results: $N=3.69(8), \sigma^{2}=0.0056(5) \AA^{2}$, $\Delta r=-0.015(3) \AA$, and $\Delta E_{0}=2.64(19) \mathrm{eV}$. The correlation factor of the fit is $R=0.00165$. The results of the quick first shell theory for these EXAFS data suggest that the Fe centres have on average a significantly lower coordination number than 6 , and that on average the oxygen atoms are closer to the Fe ions. The mean length of the Fe-O bonds is 1.94(3) A.

These findings seem to support the DFT model for the studied glass. And indeed when using this cluster for the calculation of EXAFS functions with FEFF 9, and performing a subsequent fit of the calculated EXAFS functions to the experimental data, an excellent agreement is achieved, $c f$. Fig. 11. The fit is carried out directly in the $k$-space. The fitting range is $2 \AA^{-1}$ to $9 \AA^{-1}$ with $k_{\mathrm{w}}=1,2$, and 3 including only single scattering paths up to $3.3 \AA$. The calculations of the simulated EXAFS spectrum have to be performed on all three Fe centres of the DFT model, which for the purpose of the EXAFS study are labelled: Fe1, Fe2 (iron atoms in the ring) and $\mathrm{Fe} 3$. The proper superposition of the calculated
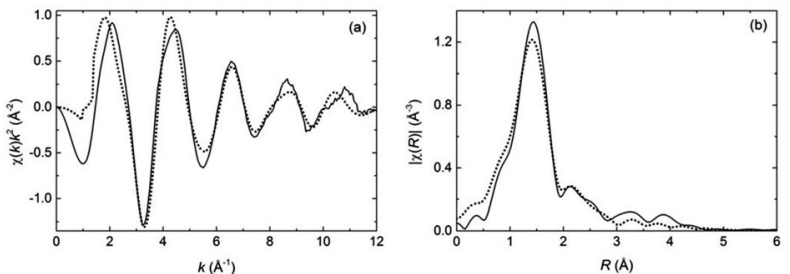

Fig. 11 (a) Experimental EXAFS spectrum in $k$-space (solid) and the calculated spectrum from the DFT model (dotted); (b) the corresponding Fourier transformed EXAFS curves in $R$-space. 
EXAFS curves is done by mathematical constraints in the fitting model. These are amongst others the abundances of each Fe site in the material, 0.35 for $\mathrm{Fe} 1,0.35$ for $\mathrm{Fe} 2$ and 0.3 for $\mathrm{Fe} 3$. Due to the nature of the DFT model Fe3 is not suitable to be included in the fitting model, because it bridges two such clusters. Thus, it has an incomplete surrounding in the single chain model structure being used. Therefore, Fe2, which has a 5 -fold symmetry, too, has to be taken instead. So the fraction of $\mathrm{Fe} 2$ is then 0.65. However, the Fe ion at the Fe3 site is divalent whereas the $\mathrm{Fe}$ ion at the $\mathrm{Fe} 2$ site is trivalent. $\mathrm{Fe}^{2+}$ is known to have in average longer $\mathrm{Fe}-\mathrm{O}$ bonds by $0.2 \AA$ than $\mathrm{Fe}^{3+}$. This fact has to be taken into account when discussing the lattice distortion factor $\Delta r$ for the Fe2 site. Furthermore, when one wants to combine two amplitudes of FEFF calculations via a fixed ratio, one has to keep in mind that FEFF assigns always an amplitude of 100 to the first scattering part. This has to be corrected by finding a scattering path to the same atom for each calculation. In this case these are Fe1-P2 and Fe2-P2, where P2 is atom no. 9 in the DFT model. These are scattering paths with an amplitude of 42.91 and an effective radius of $2.9925 \AA$ for $\mathrm{Fe} 1$ and an amplitude of 43.05 and an effective radius of $2.6074 \AA$ for Fe2. Assuming that the scattering amplitude is reversely proportional to the square of the scattering path radius, one can easily calculate the correction factor by which the two amplitudes of the FEFF calculations are related, by multiplying the ratios of the calculated scattering amplitudes, the squares of the respective path radii and the relative abundances, $43.05 / 42.91 \times(2.6074)^{2} /(2.9925)^{2} \times 0.65 / 0.35=1.41$. This coefficient allows the use of only one free parameter for the amplitude $(A)$ in the fitting model. The other fit parameters are: the DebyeWaller factor $\left(\sigma^{2}\right)$ and the bond length distortion $(\Delta r)$ for each Fe site and one inner core potential correction factor $\left(\Delta E_{0}\right)$ for the whole fitting model. These are in total 6 free fit parameters. The results of the fitting procedure are presented in Table 2.

As expected the $\Delta r$ parameter for the Fe2 site is significantly larger than for the $\mathrm{Fe} 1$ site, because it contains also the correction for the 5-fold coordinated $\mathrm{Fe}^{2+}$ ion placed in the $\mathrm{Fe} 3$ site. If one assumes that the lattice distortion at the 5-fold coordinated $\mathrm{Fe}^{3+}$ ion placed in the $\mathrm{Fe} 2$ site is of the same order as that for the 4 -fold coordinated $\mathrm{Fe}^{3+}$ ion placed in the Fe1 site, one gets estimated values for the mean bond length elongation at the Fe3 site, 5 -fold coordinated $\mathrm{Fe}(\mathrm{II}), \Delta r=0.282 \AA$; a value expected for the bond length difference between divalent and trivalent ions. In general the mean distance of all $\mathrm{Fe}-\mathrm{O}$ bonds in the fitted model amounts to $1.94 \AA$, which is in agreement with the quick first shell theory.

The DFT model was used for the calculation of a XANES spectrum in order to reproduce the experimental one. The XANES spectrum is very sensitive to small changes in the local symmetry, as reported elsewhere. ${ }^{44}$ Additionally, calculations of the XANES spectra using the FEFF 9 code do not take any free parameters and use a full-multiple scattering algorithm rather than a simple path expansion as in the case of EXAFS calculations. Therefore, this is a good probe for the verification of the fit results obtained from the EXAFS analysis and the structural model in general. Like in the case of EXAFS calculations, separate calculations of the theoretical XANES spectra are done at each Fe site of the cluster. Due to the very same reasons as for the EXAFS case the $\mathrm{Fe} 2$ site (5-fold coordinated $\mathrm{Fe}^{3+}$ ) and the Fe3 site (5-fold coordinated $\mathrm{Fe}^{2+}$ ) are combined and represented by one calculation. A superposition of two calculations combined by the same coefficient as for the EXAFS case is then representing the calculated XANES curve, as presented in Fig. 12. As one can see that the curve reproduces all significant spectral features of the experimental spectra, despite the fact in the simulations the larger interatomic distance at the 5-fold coordinated $\mathrm{Fe}^{2+}$ site was not taken into account. This and the EXAFS analysis show that the DFT model is representative of the local structure of the investigated $60 \mathrm{P}_{2} \mathrm{O}_{5}-40 \mathrm{Fe}_{2} \mathrm{O}_{3}$ glass.

\section{Discussion}

The conducted DFT simulations and structural studies of the $60 \mathrm{P}_{2} \mathrm{O}_{5}-40 \mathrm{Fe}_{2} \mathrm{O}_{3}$ glass allowed us to propose a structural model of the glass. The starting point in presented considerations was the $\alpha-\mathrm{FePO}_{4}$ crystal structure which is built of $\left[\mathrm{PO}_{4}\right]^{+}\left[\mathrm{FeO}_{4}\right]^{-}$ tetrahedra joined and sharing common vertices. The $\left[\mathrm{PO}_{4}\right]^{+}$has an unbalanced charge +1 but on the other side $\left[\mathrm{FeO}_{4}\right]^{-}$has a charge -1 , so both of them compensate their charges and there are no $\mathrm{P}=\mathrm{O}$ double bonds. In this case only $\mathrm{Q}_{4}$ units exist. The $\left[\mathrm{PO}_{4}\right]\left[\mathrm{FeO}_{4}\right]$ tetrahedra form even membered rings and alternate each other. Increasing $\mathrm{P}_{2} \mathrm{O}_{5}$ content results in the formation of smaller rings, as proposed in Fig. 2a, and in the case of the studied glass the structure could be built only using them to maintain the desired stoichiometry of the melt. There is enough oxygen to transform one of the $\mathrm{Q}_{4}$ units to the $\mathrm{Q}_{3}$ unit, which leads to a small unbalanced charge on $\left[\mathrm{FeO}_{4}\right]$. The increasing oxygen concentration in the melt increases the tendency for further transformation of $\mathrm{Q}_{4}$ to $\mathrm{Q}_{3}$ and even to $\mathrm{Q}_{2}$ units, which changes the glass structure from a three dimensional cross-linked network to polymer like chains. In this case the charge of $\left[\mathrm{FeO}_{4}\right]$ tetrahedra is fully unbalanced. These rings join together and can build the glass, as shown in Fig. 2b. The reducing conditions during the synthesis of the glass reduce a part of $\mathrm{Fe}^{3+}$ ions to $\mathrm{Fe}^{2+}$ ions, which is observed as

Table 2 Best fit parameter values and the correlation factor of the EXAFS analysis using the DFT model

\begin{tabular}{|c|c|c|c|c|c|}
\hline & $A$ & $\sigma^{2}\left(\AA^{2}\right)$ & $\Delta r(\AA)$ & $\Delta E_{0}(\mathrm{eV})$ & $R$ \\
\hline Fe1-Fe(III) 4-fold coordinated & $0.38(4)$ & $0.001(2)$ & $0.018(9)$ & $7.2(9)$ & 0.052 \\
\hline $\mathrm{Fe} 2-\mathrm{Fe}$ (II) and $\mathrm{Fe}$ (III) 5-fold coordinated & $0.55^{a}$ & $0.009(4)$ & $0.14(2)$ & & \\
\hline
\end{tabular}

${ }^{a} A_{\mathrm{Fe} 2}$ value not fitted, but connected to $A_{\mathrm{Fe} 1}$ by the relation $A_{\mathrm{Fe} 2}=1.41 A_{\mathrm{Fe} 1}$ (see text). 


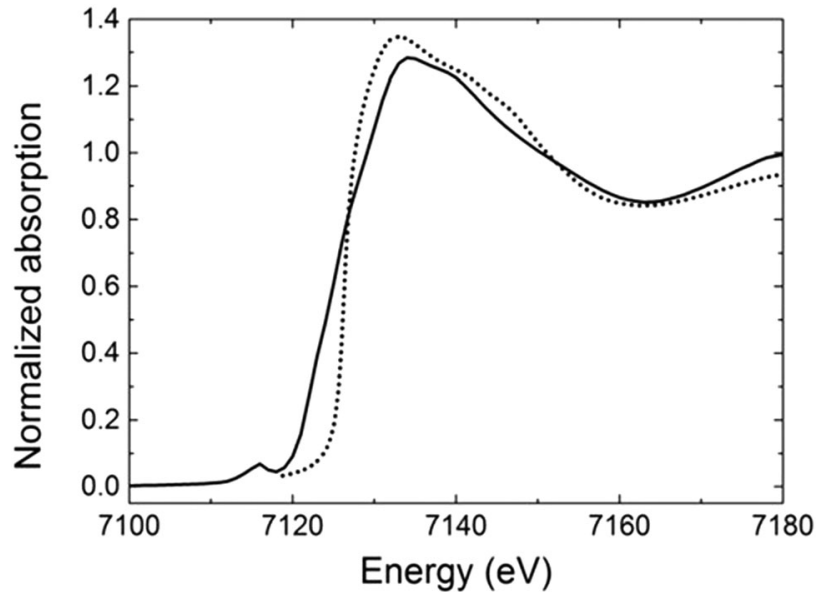

Fig. 12 The experimental XANES spectrum (solid) and the calculated spectrum (dotted) based on the DFT model cluster.

the disintegration of some rings and results in the formation of the units shown in Fig. 3a. In this case the melt is richer in oxygen and all $\mathrm{Q}_{4}$ units are transformed to $\mathrm{Q}_{3}$ and $\mathrm{Q}_{2}$ depending on the $\mathrm{Fe}^{2+}$ ion concentration, which changes the glass network from a three dimensional cross-linked network to a chain-like structure. Thus, iron is changing its role from a glass structure former to a glass modifier. In the proposed glass unit $\mathrm{Fe}^{2+}$ ions can behave as a typical glass network modifier joined to non-bridging oxygen atoms and cross-link glass chains, which can increase the stability of the glass structure or can be a charge compensator of $\left[\mathrm{FeO}_{4}\right]^{-}$tetrahedra in the rings. To fully compensate the unbalanced $\left[\mathrm{FeO}_{4}\right]^{-}$ tetrahedra at least approximately $33 \%$ of iron atoms should be reduced from $\mathrm{Fe}^{3+}$ to $\mathrm{Fe}^{2+}$, as in the case of the synthesized glass. It is worth mentioning that the total energy per atom of the unit is lower than the energy of the ring, which suggests that the unit is more preferable and additionally enhances the reduction of iron.

Previous investigations of the same base glass but loaded with caesium revealed that in the obtained glasses there were almost only $\mathrm{Fe}^{3+}$ ions. ${ }^{14,15}$ It is interesting that no special structural changes were observed with increasing $\mathrm{Cs}_{2} \mathrm{O}$ content in the base glass up to $22 \mathrm{~mol} \%$. Further increase of the caesium content elicits rebuilding of the glass structure. ${ }^{15}$ The transformation and melting temperatures both rise with increasing $\mathrm{Cs}_{2} \mathrm{O}$ content up to $22 \mathrm{~mol} \%$ and above this value they are reduced. The increase of these temperatures is unusual and cannot be explained assuming Cs as a typical glass structure modifier.

Due to the lack of $\mathrm{Fe}^{2+}$ ions, the structure of these glasses can also be described by the proposed rings. In this case the $\mathrm{Cs}^{+}$ion can be a charge compensator for the $\left[\mathrm{FeO}_{4}\right]^{-}$which strongly bonds them. Moreover, one $\mathrm{O}^{2-}$ anion introduced by $\mathrm{Cs}_{2} \mathrm{O}$ changes the $\mathrm{Q}_{4}$ to $\mathrm{Q}_{3}$ units. Thus one ring needs two $\mathrm{Cs}^{+}$ions to fully compensate its charge and to get one $\mathrm{O}^{2-}$ anion which transforms two $\mathrm{Q}_{4}$ to $\mathrm{Q}_{3}$ units. In this case the glass is built only of $\mathrm{Q}_{3}$ units. The situation in which one $\mathrm{Cs}_{2} \mathrm{O}$ particle falls in one ring corresponds to exactly $22 \mathrm{~mol} \%$ concentration of $\mathrm{Cs}_{2} \mathrm{O}$ in the glass. The charge balancing role of $\mathrm{Cs}^{+}$stabilises the rings, fills the voids in the glass, increases its density as reported ${ }^{14,15}$ and makes the structure more rigid, which results in an increase of both transformation and melting temperatures. A further increase of the $\mathrm{Cs}_{2} \mathrm{O}$ content leads to breaking of Fe-O-P bonds and shortening of the chains, which can be observed as the rebuilding of the glass structure. The structural change makes the structure more flexible, which causes a reduction of the above-mentioned temperatures.

Similar results like for $\mathrm{Cs}_{2} \mathrm{O}$ were previously observed in studies over the immobilization of $\mathrm{Na}_{2} \mathrm{SO}_{4}$, but the rebuilding of the structure was suggested if $\mathrm{Na}_{2} \mathrm{O}$ concentration in the glass exceeds about $30 \mathrm{~mol} \% .{ }^{16}$ In these studies the base glass was synthesised under the same conditions as in this paper, which let us assume a similar content of $\mathrm{Fe}^{2+}$ cations like in the investigated $60 \mathrm{P}_{2} \mathrm{O}_{5}-$ $40 \mathrm{Fe}_{2} \mathrm{O}_{3}$ glass. If all of the $\mathrm{Fe}^{2+}$ cations act as glass modifiers and can cross-link the chains built of the proposed units, then two $\mathrm{Na}^{+}$ cations are required in the ring in order to fully compensate the charge of the $\left[\mathrm{FeO}_{4}\right]^{-}$, and one $\mathrm{O}^{2-}$ anion transforms two $\mathrm{Q}_{3}$ units to $\mathrm{Q}_{2}$. There is still a possibility of joining one $\mathrm{Q}_{3}$ unit with one $\mathrm{Na}^{+}$ cation. The higher concentration of $\mathrm{Na}_{2} \mathrm{O}$ causes the chains built of the structural units to break and separate themselves, which can be observed as the rebuilding of the glass structure. Thus the proposed structural unit is able to join about $1.5 \mathrm{Na}_{2} \mathrm{O}$ particles per unit without complete separation of the glass chain, which gives approximately $30 \mathrm{~mol} \%$ of $\mathrm{Na}_{2} \mathrm{O}$.

According to the obtained results of natural ionicity the most covalent bond is the $\mathrm{P}-\mathrm{O}$ bond, which makes it rigid, leading to the formation of little distorted tetrahedra. On the other hand, the $\mathrm{Fe}^{3+}-\mathrm{O}$ bond is much more ionic in its nature, thus more flexible. Therefore the $\left[\mathrm{FeO}_{4}\right]$ tetrahedra can be much more distorted and the glass network can bend on them in order to accommodate different elements. The iron-phosphate glasses belong to the group of magnetic oxide glasses in which magnetic moments are spatially distributed in a disordered fashion like spin glass. The magnetic structure of these glasses is quite complex and confirms the presence of speromagnetic ordering. ${ }^{11-13}$ The magnetic correlation function obtained by the neutron scattering method shows the existence of negative peaks at 3.7 $\AA$ and 5.8-5.9 A. This suggests that the average magnetic moment of the atoms at these distances tends to be anti-parallel and the broad positive effect at 8-10 distance. ${ }^{10}$ The $60 \mathrm{P}_{2} \mathrm{O}_{5}-40 \mathrm{Fe}_{2} \mathrm{O}_{3}$ glasses ${ }^{11}$ are similar to the glass studied in this paper. Therefore, the same structural model built of the units which are joined in long chains, can be applied. The distance between two iron atoms in the unit is $3.66 \AA$ and the magnetic moments of these iron atoms are coupled antiferromagnetically, as expected. Every iron atom in the ring has the next iron atoms at a distance $5.45 \AA$ and $7.49 \AA$ from the next structural unit in the chain. If the magnetic moments of the atoms at the 5.45 A distance are anti-parallel, the magnetic moments of the atoms at a further distance of $7.49 \AA$ will have to be parallel to maintain anti-parallel coupling of the magnetic moments in the ring. This explains the magnetic structure of the iron-phosphate glasses.

\section{Conclusions}

A structural model of the $60 \mathrm{P}_{2} \mathrm{O}_{5}-40 \mathrm{Fe}_{2} \mathrm{O}_{3}$ glass is proposed, according to which, the glass is built of two kinds of structural units depending on the $\mathrm{Fe}^{3+} / \mathrm{Fe}^{2+}$ ratio. The starting point of the 
model is the crystal structure of $\alpha-\mathrm{FePO}_{4}$, which is the main crystal phase in the case of iron-phosphate glasses with high $\mathrm{Fe}^{3+}$ content. The presented model anticipates three iron sites i.e. one site for $\mathrm{Fe}^{2+}$, which can be highly distorted with mean coordination number 5 , and two sites for $\mathrm{Fe}^{3+}$, which are part of the rings. In these sites iron is placed in tetrahedral coordination, but higher coordination like 5 is also possible. Thus the glass, depending on the $\mathrm{Fe}^{2+}$ concentration, can be built of $\alpha-\mathrm{FePO}_{4}$-like regions. The obtained $\mathrm{Fe}^{3+}-\mathrm{O}$ bond ionicity is lower than the $\mathrm{Fe}^{2+}-\mathrm{O}$, but considerably higher than that of $\mathrm{P}^{5+}-\mathrm{O}$. This makes the $\mathrm{Fe}^{3+}-\mathrm{O}$ bonds more flexible than the $\mathrm{P}^{5+}-\mathrm{O}$ bonds, which leads to a higher distortion of the $\left[\mathrm{FeO}_{4}\right]$ tetrahedra than of $\left[\mathrm{PO}_{4}\right]$. On the other hand, an increase of the glass network flexibility conduces to much easier accommodation of waste constituents, leading to a high waste loading possibility of the glass.

According to the model, alkali metals function as charge compensators up to $20-30 \% \mathrm{~mol}$ concentration and are strongly bonded to the glass. This manifests itself as chemical durability of the glass and an increase of the glass transformation temperature in this region.

Moreover, the presented model can also explain the complicated magnetic structure of the studied glass. Finally, it is worth mentioning that the proposed theoretical considerations are in very good agreement with the structural studies presented in this work.

\section{Acknowledgements}

The work was supported partially by the National Science Centre of Poland project no. N N507 235740 and partially by the National Centre for Research and Development of Poland as a part of strategic research project Technologies Supporting Development of Safe Nuclear Energy. The computations were conducted with the support of PL-Grid Infrastructure.

\section{References}

1 I. W. Donald, Glass Technol., 2007, 48, 155-163.

2 I. Ojovan, W. Lee and W. Lee, An Introduction to Nuclear Waste Immobilisation, Elsevier Science, 2010.

3 I. Wacawska and M. Szumera, J. Therm. Anal. Calorim., 2010, 101, 423-427.

4 R. K. Brow, J. Non-Cryst. Solids, 2000, 263-264, 1-28.

5 C.-W. Kim and D. E. Day, J. Non-Cryst. Solids, 2003, 331, 20-31.

6 P. A. Bingham, R. J. Hand and C. R. Scales, Symposium Scientific Basis for Nuclear Waste Management XXIX, 2006.

7 U. Hoppe, J. Non-Cryst. Solids, 1996, 195, 138-147.

8 J. Shelby, Introduction to Glass Science and Technology, Royal Society of Chemistry, 2005.

9 F. Wedgwood and A. Wright, J. Non-Cryst. Solids, 1976, 21, 95-105.

10 G. Marasinghe, M. Karabulut, C. Ray, D. Day, M. Shumsky, W. Yelon, C. Booth, P. Allen and D. Shuh, J. Non-Cryst. Solids, 1997, 222, 144-152.
11 A. C. Wright, R. N. Sinclair, J. L. Shaw, R. Haworth, G. K. Marasinghe, D. E. Day, P. A. Bingham, S. D. Forder, G. J. Cuello and H. E. Fischer, Phys. Chem. Glasses: Eur. J. Glass Sci. Technol., Part B, 2012, 53, 227-244.

12 J. L. Shaw, A. C. Wright, R. N. Sinclair, G. K. Marasinghe, D. Holland, M. R. Lees and C. R. Scales, J. Non-Cryst. Solids, 2004, 345-346, 245-250.

13 H. Akamatsu, S. Oku, K. Fujita, S. Murai and K. Tanaka, Phys. Rev. B: Condens. Matter Mater. Phys., 2009, 80, 134408.

14 K. Joseph, M. Premila, G. Amarendra, K. G. Kutty, C. Sundar and P. V. Rao, J. Nucl. Mater., 2012, 420, 49-53.

15 K. Joseph, K. G. Kutty, P. Chandramohan and P. V. Rao, J. Nucl. Mater., 2009, 384, 262-267.

16 P. Stoch, M. Ciecinska and A. Stoch, J. Therm. Anal. Calorim., 2014, 117, 197-204.

17 H. Riesemeier, K. Ecker, W. Görner, B. Müller, M. Radtke and M. Krumrey, X-Ray Spectrom., 2005, 34, 160-163.

18 B. Ravel and M. Newville, J. Synchrotron Radiat., 2005, 12, 537-541.

19 S. M. Heald and E. A. Stern, Phys. Rev. B: Solid State, 1977, 16, 5549-5559.

20 G. Bunker, Introduction to XAFS: A Practical Guide to X-ray Absorption Fine Structure Spectroscopy, Cambridge University Press, 2010.

21 C. Wivel and S. Morup, J. Phys. E: Sci. Instrum., 1981, 14, 605. 22 H. Alberto, J. P. da Cunha, B. Mysen, J. Gil and N. A. de Campos, J. Non-Cryst. Solids, 1996, 194, 48-57.

23 M. J. Frisch, G. W. Trucks, H. B. Schlegel, G. E. Scuseria, M. A. Robb, J. R. Cheeseman, G. Scalmani, V. Barone, B. Mennucci, G. A. Petersson, H. Nakatsuji, M. Caricato, X. Li, H. P. Hratchian, A. F. Izmaylov, J. Bloino, G. Zheng, J. L. Sonnenberg, M. Hada, M. Ehara, K. Toyota, R. Fukuda, J. Hasegawa, M. Ishida, T. Nakajima, Y. Honda, O. Kitao, H. Nakai, T. Vreven, J. A. Montgomery Jr, J. E. Peralta, F. Ogliaro, M. Bearpark, J. J. Heyd, E. Brothers, K. N. Kudin, V. N. Staroverov, R. Kobayashi, J. Normand, K. Raghavachari, A. Rendell, J. C. Burant, S. S. Iyengar, J. Tomasi, M. Cossi, N. Rega, J. M. Millam, M. Klene, J. E. Knox, J. B. Cross, V. Bakken, C. Adamo, J. Jaramillo, R. Gomperts, R. E. Stratmann, O. Yazyev, A. J. Austin, R. Cammi, C. Pomelli, J. W. Ochterski, R. L. Martin, K. Morokuma, V. G. Zakrzewski, G. A. Voth, P. Salvador, J. J. Dannenberg, S. Dapprich, A. D. Daniels, Ö. Farkas, J. B. Foresman, J. V. Ortiz, J. Cioslowski and D. J. Fox, Gaussian 09 Revision D.01, Gaussian Inc., Wallingford CT, 2009.

24 A. C. Wright, R. N. Sinclair, J. L. Shaw, R. Haworth, G. K. Marasinghe and D. E. Day, Phys. Chem. Glasses: Eur. J. Glass Sci. Technol., Part B, 2008, 49, 1-7.

25 U. Hoppe, G. Walter, R. Kranold and D. Stachel, J. Non-Cryst. Solids, 2000, 263-264, 29-47.

26 B. Al-Hasni and G. Mountjoy, J. Non-Cryst. Solids, 2011, 357, 2775-2779.

27 B. M. Al-Hasni, G. Mountjoy and E. Barney, J. Non-Cryst. Solids, 2013, 380, 141-152.

28 J. P. Foster and F. Weinhold, J. Am. Chem. Soc., 1980, 102, 7211-7218. 
29 F. Weinhold and C. R. Landis, Discovering Chemistry with Natural Bond Orbitals, John Wiley and Sons, Inc., 2012.

30 L. Zhang and R. K. Brow, J. Am. Ceram. Soc., 2011, 94, 3123-3130.

31 Y. Lai, X. Liang, S. Yang, J. Wang, L. Cao and B. Dai, J. Mol. Struct., 2011, 992, 84-88.

32 C. Kim, C. Ray, D. Zhu, D. Day, D. Gombert, A. Aloy, A. MoguMilankovi and M. Karabulut, J. Nucl. Mater., 2003, 322, 152-164.

33 C.-W. Kim and D. E. Day, J. Non-Cryst. Solids, 2003, 331, 20-31.

34 T. Jermoumi, M. Hafid, N. Niegisch, M. Mennig, A. Sabir and N. Toreis, Mater. Res. Bull., 2002, 37, 49-57.

35 C. Cramer, Essentials of Computational Chemistry: Theories and Models, Wiley, 2005.

36 P. Stoch, M. Ciecinska, P. Zachariasz, J. Suwalski, L. Gorski and T. Wojcik, Nukleonika, 2013, 58, 63-66.
37 I. Shino and Z. Li, Am. Mineral., 1998, 83, 1316-1322.

38 U. Hoppe, M. Karabulut, E. Metwalli, R. K. Brow and P. Jóvári, J. Phys.: Condens. Matter, 2003, 15, 6143.

39 J. Millet, C. Virely, M. Forissier, P. Bussiére and J. Vedrine, Hyperfine Interact., 1989, 46, 619-628.

40 L. Aldon, A. Perea, M. Womes, C. Ionica-Bousquet and J.-C. Jumas, J. Solid State Chem., 2010, 183, 218-222.

41 H. Bertagnolli and T. S. Ertel, Angew. Chem., Int. Ed. Engl., 1994, 33, 45-66.

42 J. J. Rehr, J. J. Kas, F. D. Vila, M. P. Prange and K. Jorissen, Phys. Chem. Chem. Phys., 2010, 12, 5503-5513.

43 M. Karabulut, G. Marasinghe, C. Ray, D. Day, G. Waddill, C. Booth, P. Allen, J. Bucher, D. Caulder and D. Shuh, J. Non-Cryst. Solids, 2002, 306, 182-192.

44 J. Rehr and A. Ankudinov, Coord. Chem. Rev., 2005, 249, 131-140. 